\title{
Correlations between Molecular Landscape and Sonographic Image of Different Variants of Papillary Thyroid Carcinoma
}

\author{
Andrzej Lewiński ${ }^{1,2, *}$, Zbigniew Adamczewski ${ }^{1,2}$ (), Arkadiusz Zygmunt ${ }^{1,2}$, \\ Leszek Markuszewski ${ }^{2}$, Małgorzata Karbownik-Lewińska ${ }^{2,3}$ and Magdalena Stasiak ${ }^{2}$ (D) \\ 1 Department of Endocrinology and Metabolic Diseases, Medical University of Lodz, 93-338 Lodz, Poland; \\ zbadam@o2.pl (Z.A.); arkadiusz.zygmunt@umed.lodz.pl (A.Z.) \\ 2 Department of Endocrinology and Metabolic Diseases, Polish Mother's Memorial Hospital—Research \\ Institute, 93-338 Lodz; Poland; leszekmarkuszewski@gmail.com (L.M.); \\ mkarbownik@hotmail.com (M.K.-L.); mstasiak33@gmail.com (M.S.) \\ 3 Chair and Department of Oncological Endocrinology, Medical University of Lodz, 90-752 Lodz, Poland \\ * Correspondence: alewin@csk.umed.lodz.pl or andrzej.lewinski@umed.lodz.pl; Tel.: +48-42-271-1141; \\ Fax: +48-42-271-1140
}

Received: 24 September 2019; Accepted: 6 November 2019; Published: 8 November 2019

\begin{abstract}
Papillary thyroid carcinoma (PTC), the most common thyroid cancer, is predominantly driven by mutations in BRAF (primarily p. V600E) and RAS oncogenes. Ultrasound (US) examination provides significant diagnostic data in the management of thyroid nodules, as many sonographic features of thyroid lesions are correlated with the potential risk of thyroid carcinoma. The aim of the study was to analyze the current literature in regard to the potential associations between genetic landscape and sonographic features of PTC. Based on the current literature, sonographic features of PTCs correlate with their molecular drivers, particularly between tumors harboring $B R A F^{V 600 E}$ versus activating $R A S$ mutations, although many of these findings appear to be dependent on the tumor variant. Suspicious US findings, such as hypoechogenicity, spiculated/microlobulated margins, non-parallel orientation/taller-than-wide shape, and the presence of microcalcifications, are typical for PTC positive for $B R A F^{V 600 E}$ mutations. On the contrary, tumors with $R A S$ mutations are most frequently hypo- or isoechoic and ovoid-to-round in shape, with smooth margins and without calcifications. There are also some US features typical for PTCs harboring other mutations, including $B R A F^{K 601 E}, R E T / P T C$ rearrangements, PAX8-PPAR $\gamma, C T N N B 1$, and APC. However, further research is necessary, as some rare PTC variants still cannot be reliably analyzed due to the scarce published data.
\end{abstract}

Keywords: papillary thyroid carcinoma; ultrasound; sonographic features; $B R A F^{V 600 E}$ mutations; $R A S$ mutation; genetic drivers; classic variant; follicular variant

\section{Introduction}

Papillary thyroid carcinoma (PTC) is the most common thyroid cancer, accounting for over 90\% of all thyroid malignancies. Several mutations comprise the underlying molecular etiology of PTC, including BRAF (predominantly p. V600E) and activating RAS mutations. Less frequent drivers include other non-V600E BRAF mutations, APC and CTNNB1 mutations, as well as NTRK, ALK, and $B R A F$ fusions [1].

Ultrasound (US) examination is a precise diagnostic tool in the management of thyroid nodules as many sonographic features of thyroid lesions provide information about the potential risk of thyroid carcinoma. Moreover, sheer wave sonoelastography was demonstrated to provide significant additional data facilitating the assessment of the risk of malignancy [2]. Many US-based classifications 
of thyroid nodules have been formulated to facilitate the selection of lesions for fine needle aspiration biopsy (FNAB) [3-8]. The majority of the classifications are consistent in regard to the most suspicious features, including hypoechogenicity, blurred margins, microcalcifications, taller-than-wide shape, and — undoubtedly - the presence of metastatic lymph nodes.

It seems reasonable to believe that the presence of a specific mutation leading to PTC may affect the ultrasound image of the lesion. Recently, we demonstrated that genetic drivers can significantly affect the US pattern of thyroid lesions in subacute thyroiditis [9]. It can be expected that such an association would be even more pronounced in thyroid malignant lesions. Several authors have attempted to analyze the correlation between the molecular landscape of thyroid carcinoma and the ultrasound image. Unfortunately, these reports are scarce and significant discrepancies between the authors' observations are often present.

The aim of this review is to answer the question whether-on the basis of the most recent literature-there is a relationship between the genetic drivers of PTCs and their ultrasound image. A study selection flowchart is available in the Supplementary Material—Figure S1.

\section{Thyroid Tumor Classifications}

\subsection{New Aspects of Pathological Classifications of Thyroid Carcinoma}

The most recent improvements in thyroid nodule classifications began in March 2015, when the Endocrine Pathology Society reclassified encapsulated follicular variant of PTC (EFV PTC) or clearly delimited non-invasive follicular variants of papillary thyroid carcinoma under the proposed nomenclature "non-invasive follicular thyroid neoplasm with papillary-like nuclear features" (NIFTP) [10,11]. This reclassification was approved in 2017 by the American Thyroid Association and was incorporated into the 2017 WHO classification of tumors of the thyroid gland under a new class of diagnoses "other encapsulated follicular-patterned thyroid tumors" [3,11].

The new WHO classification schema also introduced two additional diagnoses under this new category: A follicular tumor of uncertain malignant potential (FT-UMP) and a well-differentiated tumor of uncertain malignant potential (WDT-UMP), both of which were borderline between follicular adenoma and carcinoma or follicular adenoma and a follicular variant of papillary carcinoma. In these new entities, nuclear features of PTC as well as lack of capsular or vascular invasion are not so clearly expressed as in NIFTP [11].

Importantly, a new classification of PTC variants was provided, with the following variants being included: (1) Conventional/classic variant; (2) papillary microcarcinoma; (3) encapsulated PTC — applicable to fully encapsulated classic PTC; (4) follicular variant (FV)—invasive PTC with an exclusively or almost exclusively follicular pattern, and no developed papillae; (5) diffuse sclerosing variant; (6) tall cell variant; (7) columnar cell variant; (8) cribriform-morular variant; (9) hobnail variant-new entity; (10) PTC with fibromatosis/fascitis-like; (11) solid/trabecular variant; (12) oncocytic variant; (13) spindle cell variant and giant cell carcinoma; (14) clear cell variant; (15) Warthin-like variant; and (16) combined papillary and medullary carcinoma [11]. The above classification of thyroid tumors is extremely detailed and includes 16 variants of papillary thyroid carcinoma, 5 of which are-in contrast to the others-characterized by a particularly poor prognosis (aggressive biological behavior). These are tall cell variant (being definitely the most common among the aggressive variants), diffuse sclerosing variant, columnar cell variant, cribriform-morular variant, and hobnail variant (new entity) [11]. Cribriform-morular variant is considered by many authors as more favorable [12], but in most cases, its course is very aggressive despite the "benign-like" sonographic pattern.

\subsection{Sonographic Classifications of Thyroid Nodules}

In recent years, several classifications of thyroid nodules based on the presence of US high-risk features were introduced [3-8]. The aim of these classifications is to limit the number of unnecessary FNAB and, at the same time, to facilitate the proper qualification to FNAB of all lesions with the potential 
US risk of malignancy. The most commonly used classifications are prepared by the American Thyroid Association (ATA) [3], American Association of Clinical Endocrinologists (AACE/ACE/AME) [13], American College of Radiology (ACR) [14], European Thyroid Association (ETA) [3], and Korean Society of Thyroid Radiology [5].

ATA classification distinguishes five groups of US risk - benign, very low suspicion, low suspicion, intermediate suspicion, and high suspicion [3]. The last group includes nodules that are solid and hypoechoic, or partially cystic with a solid hypoechoic component, with one or more of the following features: Irregular margins, microcalcification, taller-than-wide shape, rim calcification with small extrusive soft tissue component, and evidence of extrathyroidal extension. Hypoechoic solid nodules without any of these additional features are considered as part of the intermediate suspicious group [3]. Similar US features allow classification of the lesion as high risk in the EU-TIRADS classification (EU-TIRADS 5 category) [4]. All classifications consider smooth margins and isoechogenicity as unsuspicious US features; however, some aggressive variants of PTC may have such a sonographic pattern. Many authors believe that point classifications better assess the real sonographic risk of the nodule. In 2013, we proposed such classification, giving 3 points for nodule augmentation and for suspicious lymph nodes; 1 point for hypoechogenicity, microcalcifications, suspicious shape, and vascularization; and 0.5 points for blurred margins, size, presence of halo, and echostructure [6-8]. The total sum of 7 points or more was considered as a high-risk sonographic pattern [6-8]. The same number of points for a highly suspicious nodule was proposed by Tessler et al. [14] in the point classification developed by ACR (ACR-TIRADS). This classification provides recommendation for FNAB for five risk classes selected on the basis of the total number of points (TR level 1-5) [14]. Recently, integration of sonoelastography into the TIRADS classification was demonstrated to increase the value risk of predicted malignancy, with a consequently different approach to further clinical investigation and management [15].

\section{Genetic Drivers of Thyroid Carcinoma}

Initiating mutations or gene fusions in the thyroid carcinoma include: $B R A F$ in PTC, N-K-H-RAS in PTC and/or follicular thyroid carcinoma (FTC), RET/PTC in PTC, and PAX8/PPAR $\gamma$ in FTC [16]. RET/PTC1, RET/PTC3, and RET/PTC4 are formed as a result of intrachromosomal rearrangements (paracentric inversions within the long arm of chromosome 10). Several other RET/PTC rearrangements result from inter-chromosomal translocations [17].

The prevalence of mutations according to the thyroid tumor type was demonstrated as follows: PTC: $B R A F$ in $40 \%$ to $45 \%, R E T / P T C$ in $6 \%$ to $30 \%$, telomerase reverse transcriptase (TERT) promoter in up to $23.5 \%$, RAS in $10 \%$ to $20 \%$, and TRK in $<5 \%$; FTC: RAS in $40 \%$ to $50 \%$, PAX8-PPAR $\gamma$ in $10 \%$ to $35 \%$, PIK3CA in $<10 \%$, and PTEN in $<10 \%$; poorly differentiated carcinoma: $R A S$ in $25 \%$ to $30 \%$; CTNNB1 in 10\% to $20 \%$, TP53 in $20 \%$ to $30 \%$, and BRAF in $10 \%$ to $15 \%$; familial forms of medullary carcinoma (MTC): RET in >95\%; and sporadic MTC: RET in $40 \%$ to $50 \%[16,18,19]$.

Some of the mutations can serve as molecular markers of the aggressiveness of differentiated thyroid carcinoma (DTC). Such markers include the presence of $>1$ driver mutation, and PIK3CA, $p 53$, CTNNB1, and TERT promoter mutations $[18,20]$.

\section{Genetic Drivers and Sonographic Pattern of Different Variants of PTC}

\subsection{BRAF Mutations}

$B R A F$ mutations have been reported in classic, Hürthle, tall cell, columnar cell, hobnail, Warthin, and diffuse sclerosing variants. $B R A F^{V 600 E}$ is a common mutation characteristic for PTC displaying a papillary or mixed follicular-papillary growth pattern [21]. Wang et al. [22] demonstrated via multivariate analysis that poorly defined margins and microcalcification were independent predictors of $B R A F^{V 600 E}$ mutation. Lee et al. [23] found that $B R A F^{V 600 E}$ mutation was associated with the following US features: Solid composition, marked hypoechogenicity, irregular margin, taller-than-wide shape, 
and the presence of microcalcifications. Similarly, Khadra et al. [24] observed that hypoechogenicity, intra-nodular calcification, and irregular nodular margins were the most predictive features of $B R A F^{V 600 E}$ positivity. Unfortunately, they did not analyze the tumor shape. Additionally, they observed that $B R A F^{V 600 E}$-positive PTCs were associated with a higher rate of lymph node metastasis and the rate of extrathyroidal extension [24]. Very recently, Colombo et al. also demonstrated a correlation between BRAF ${ }^{V 600 E}$ mutation and extrathyroidal invasion, as well as US features of the higher ATA risk category of PTC [18]. In the analysis by Rossi et al. [25], $B R A F^{V 600 E}$ mutation was associated with hypoechogenicity, microcalcifications, and a nodule diameter $<1 \mathrm{~cm}$. Kabaker et al. [26] observed that $B R A F^{V 600 E}$ positivity was associated with such suspicious US findings as a taller-than-wide shape, ill-defined margins, hypoechogenicity, micro/macrocalcifications, and an absent halo. On the contrary, $B R A F^{V 600 E}$ mutations were not associated with non-cystic composition. The authors stated that $B R A F$ mutation can be predicted with a positive predictive value of $82 \%$ when at least three of the above-mentioned suspicious US features are present [26]. A taller-than-wide shape was proven to be a useful US feature for predicting thyroid malignancy, especially when analyzed in both transverse and/or longitudinal planes [27]. Those observations were not dependent on the PTC variant, as the authors did not analyze correlations with PTC variants [22-27].

The classic variant is the most common PTC variant (32-49\%), and the BRAF V600E mutation is the most frequent $(90 \%)$ genetic driver of this variant [28-30]. A typical US pattern for this PTC subtype includes hypoechogenicity, spiculated/microlobulated margins, microcalcifications, non-parallel orientation, and mixed-type non-increased vascularity [31].

In the Hürthle cell variant, $B R A F^{V 600 E}$ was detected in tumors displaying a papillary or a mixed growth pattern but not in those with a follicular pattern [21]. In US, the lesion can be hypo- or isoechoic with smooth or spiculated/microlobulated margins. Microcalcifications are often absent, but macrocalcifications are found in $20 \%$ of tumors. A non-parallel orientation is very characteristic, and vascularity is mixed in most patients and increased in half of the cases [31].

The incidence of tall cell variant, which is also frequently (over 92\%) associated with BRAF V600E mutations, is reported as $4 \%$ to $17 \%$ of PTCs [12]. Ultrasounds reveal malignant features typical for $B R A F^{V 600 E}$ mutation, which include a solid structure, hypoechogenicity, with or without microcalcifications, a spiculated/microlobulated margin, and non-parallel orientation with frequent nodal metastass [12,31].

The very rare columnar cell variant also presents typical malignant features, and $B R A F^{V 600 E}$ mutation occurs in one-third of these PTCs [32]. Encapsulated tumors of this variant exhibit a US pattern of circumscribed hypoechoic nodules. Such cases are associated with better prognosis. Microcalcifications may be present but they are not typical. More aggressive tumors are larger hypoechoic ones, with microlobulated margins, often associated with visible extrathyroidal invasion and lymph node metastases [12,32]. Interestingly, $B R A F^{V 600 E}$ mutation is frequent in these more aggressive tumors while the encapsulated ones are often $B R A F^{V 600 E}$ negative [32]. Chen et al. [32] indicated that altered $B R A F^{V 600 E}$ is an adverse prognostic factor in the columnar cell variant due to its association with unfavorable clinicopathological characteristics. Older patient age, male gender, and distant metastasis were highly prevalent features for these BRAF-positive tumors [32]. The rare aggressive hobnail variant was reported to be associated with $B R A F^{V 600 E}$ mutation in $58 \%$ of cases. [33]. In US, these lesions are usually described as microlobulated hypoechoic nodules with microcalcifications and multiple lymph node metastases [12,33]. Tumors are often multifocal [33].

The Warthin-like variant (WV) is associated with Hashimoto's thyroiditis in $93 \%$ to $100 \%$ of all cases [12]. Typically, cells with nuclear features of papillary carcinoma line the papillary structures, with dense lymphocytic infiltration in the stalks. In this variant, $B R A F^{V 600 E}$ mutations are less frequent than in the classic variant (65\% vs. $84 \%$ ) [12], but BRAF mutation is still the most common genetic driver. The most common US features of WV PTCs are a solid composition, hypoechogenicity, and taller-than-wide shape [34,35]. The US pattern of nodules harboring $B R A F^{V 600 E}$ mutations may differ depending on the presence of Hashimoto's thyroiditis. Microcalcifications were observed as typical for 
$B R A F^{V 600 E}$-positive nodules without Hashimoto's thyroiditis while a solid nodule structure was more common in $B R A F^{V 600 E}$-positive nodules with Hashimoto's thyroiditis [36].

Papillary thyroid microcarcinoma (PTMC) constitutes approximately $30 \%$ of all PTC cases, and it is also typically associated with $B R A F$ mutation, with a US pattern typical for these mutations [28,30].

$B R A F^{V 600 E}$ mutations are rare (24\%) in the diffuse sclerosing variant (DSV) [37], but their presence significantly influences the US pattern of DSV. The challenges related to dependencies between the molecular landscape and the sonographic pattern of this subtype will be discussed further below.

On the basis of the presented literature review, PTCs harboring $B R A F^{V 600 E}$ mutations frequently demonstrate typical US high-risk features, including hypoechogenicity, microcalcifications, irregular and/or ill-defined margin, taller-than-wide shape, and extrathyroidal invasion.

A sonographic pattern typical for PTCs bearing the $B R A F^{V 600 E}$ mutation is presented in Figure 1.

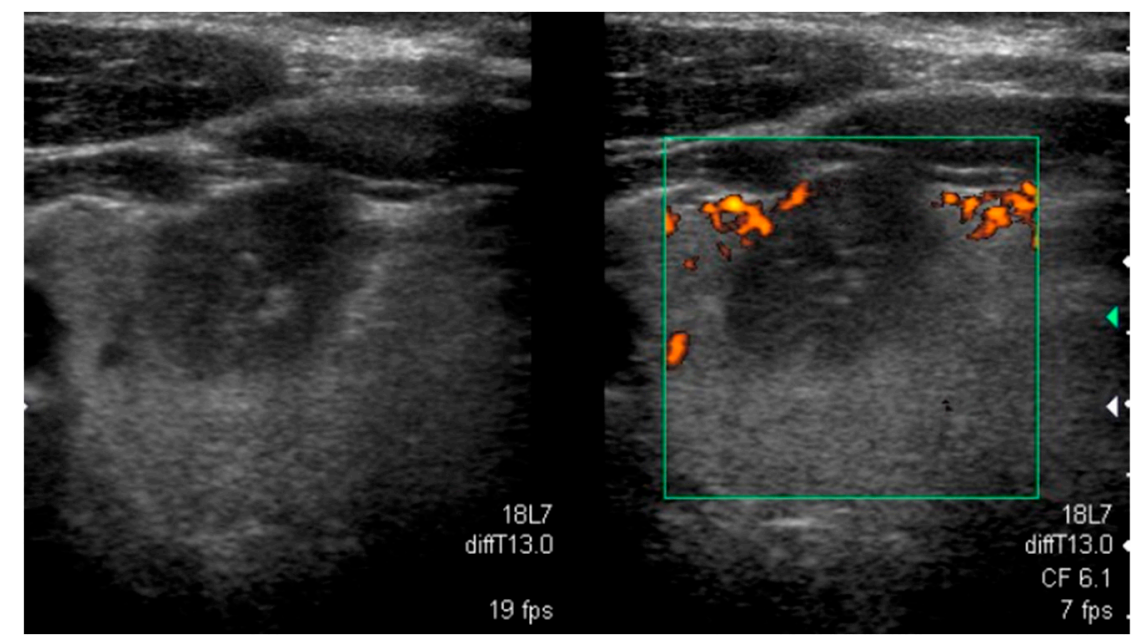

Figure 1. Typical sonographic pattern of a $B R A F^{V 600 E}$-positive papillary thyroid carcinoma hypoechoic lesion with poorly defined irregular margins and microcalcifications.

The correlations between the presence of $B R A F^{V 600 E}$ mutations and sonographic findings in PTC are widely described, although there are also a few reports in which such associations were not observed $[29,38]$. The authors of these reports analyzed the US patterns of $B R A F^{V 600 E}$-positive and -negative tumors without any assessment of the PTC variants. The authors claimed not to observe an association with the US pattern, although correlations between the presence of $B R A F^{V 600 E}$ mutations and features, such as a larger tumor size, extrathyroidal extension, and lymph node metastases, were described [29].

$B R A F^{K 601 E}$ mutations are present in most cases of the infiltrative follicular variant (FV) [12]. In US, these nodules are often hypoechoic, with spiculated/microlobulated margins and microcalcifications [31, 39]. The differences in the US pattern of FV PTC depending on genetic drivers are discussed further below.

\subsection{RET/PTC Rearrangements}

RET/PTC rearrangements are the second most common genetic alteration in PTC, mainly being a genetic driver of the classic variant. More rarely, it can be associated with other variants of PTC, especially with the diffuse sclerosing variant (DSV) $[19,40]$. The two most common types of rearrangements in PTC are paracentric inversions, RET/PTC1 and RET/PTC3. The prevalence of RET/PTC rearrangements in PTC is $6 \%$ to $30 \%$, and they occur more commonly after radiation exposure and/or in children $[18,19]$. Data on the correlation between this genetic alteration and US patterns of PTC are very scarce and frequently inconsistent $[12,19,25,37]$. Isoechogenicity was described as being more common than hypoechogenicity in nodules with RET/PTC3 rearrangement [25]. Microcalcifications are present in the majority of cases $[19,25]$. Additionally, small-sized noduled and 
lymph node metastases are also typical in US [19]. RET/PTC rearrangement is the most common genetic feature in DSV [12,19]. The diffuse sclerosing variant frequently occurs in young women [12]. Despite having a similar genetic landscape, the US patterns of DSVs and classic variants are entirely different. Characteristic features of DSV include diffuse involvement of one or both thyroid lobes (frequently, no single separated tumor nodule is present), with heterogeneous parenchyma, ill-defined margins, solid hypoechoic nodules (if it is possible to separate any nodule), and scattered microcalcifications within or without the defined nodule (a "snowstorm" pattern). Additionally, lateral nodal involvement with typical nodal microcalcifications is often found [12]. This variant may sometimes resemble chronic thyroiditis. In cytology, extensive squamous metaplasia, numerous psammoma bodies, dense lymphocytic infiltration, and stromal fibrosis are typically described. The US pattern of DSV harboring RET/PTC rearrangements seems to be different in RET/PTC1- and RET/PTC3-positive cancers. Typical diffuse involvement with scattered microcalcifications without any visible nodule is much more frequent in RET/PTC3-driven tumors. The coexistence of DSV and Hashimoto's thyroiditis is characteristic for RET/PTC1 mutations. In these last cases, microcalcifications are less frequent than in RET/PTC3 tumors [37]. BRAF ${ }^{V 600 E}$ mutations are rare (24\%) in DSVs [37] and the sonographic pattern of such tumors is quite similar to those that harbor RET/PTC1 fusions and are significantly different from those with RET/PTC3 rearrangement. In US, $B R A F^{V 600 E}$-positive DSVs are more similar to other PTCs that harbor $B R A F^{V 600 E}$ than a typical DSV pattern, as the nodules are usually clearly visible and diffuse microcalcifications occur in only $33 \%$ of cases [37]. A sonographic pattern typical for PTCs harboring RET/PTC3 rearrangement are presented in Figure 2.

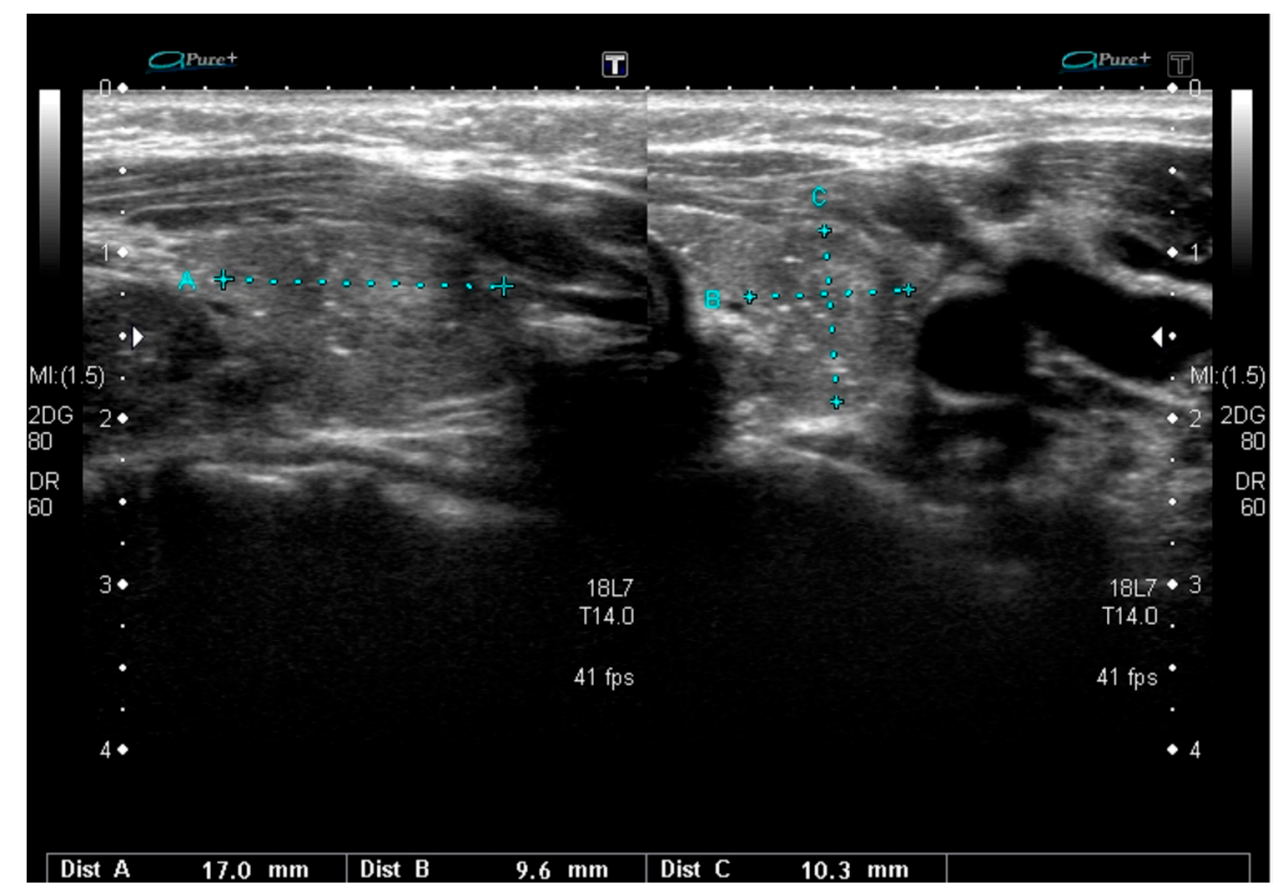

Figure 2. Sonographic pattern typical for the RET/PTC3-dependent diffuse sclerosing variant of PTC with a poorly defined area with heterogeneous parenchyma and scattered microcalcifications.

\subsection{RAS and PAX8-PPAR $\gamma$ Mutations}

RAS mutations are typical for follicular tumors (including adenomas and carcinomas), but they also occur in the follicular variant (FV) of PTC. The follicular variant is the second most common type of PTC after the classic variant $[19,40]$. Nuclear features are typical for PTC, but the growth pattern is follicular. Based on the molecular alterations and biological behavior, FV tumors were divided into two main subtypes of FV PTC: Infiltrative and encapsulated with invasion [40]. As it has already been mentioned, the lesions previously classified as the follicular variant of PTC 
(including EFVPTC) now include only those lesions with angiolymphatic or capsular invasion, or a wandering/infiltrative border. Well-demarcated or encapsulated lesions without invasion belong to the newly described entity NIFTP [11]. NIFTP is a tumor with a very good prognosis and rather benign behavior. The extent of surgical procedures can be limited in this case, although surgery is required. NIFTPs usually harbor activating RAS mutation (30-59\%), including N-RAS, H-RAS, and, less commonly, K-RAS mutations [19,40-44]. A lack of $B R A F^{V 600 E}$ mutation, detected by molecular assays or immunohistochemistry, and lack of $B R A F^{V 600 E}$-like mutations or other high-risk mutations (TERT, TP53) were included into the 2018 revised diagnostic criteria for NIFTP as secondary criteria [45]. Rosario and Mourão [46] analyzed a series of papers that reported the presence of $B R A F^{V 600 E}$ in NIFTP and demonstrated that, initially, the tumors were probably inappropriately classified as NIFTP, but in a further assessment, the presence of papillae and/or even capsular invasion was observed. $B R A F^{K 601 E}$ mutation was found in a subset of NIFTP cases $(4 \%)[47,48]$, but this group may require a similar reassessment. Although NIFTPs predominantly bear RAS mutations, tumors with other genetic alterations, such as PPAR $\gamma$ and THADA mutations, were also described [44,49]. NIFTP tumors did not present malignant US features. They are frequently isoechoic or even hyperechoic, with well-defined margins and no microcalcifications [46,50,51]. Rosario et al. [52] demonstrated that sonographic images of NIFTP thyroid nodules were classified according to ACR as TIRADS 5 only in 3.5\%. More frequently, they corresponded to TIRADS $4(67.8 \%)$ or TIRADS $3(28.5 \%)$ [52]. Similarly, only a small percentage of NIFTP lesions were classified as ATA high-risk lesions while $66 \%$ of them corresponded to the low-risk category [53]. A typical sonographic pattern of NIFTP is presented in Figure 3.

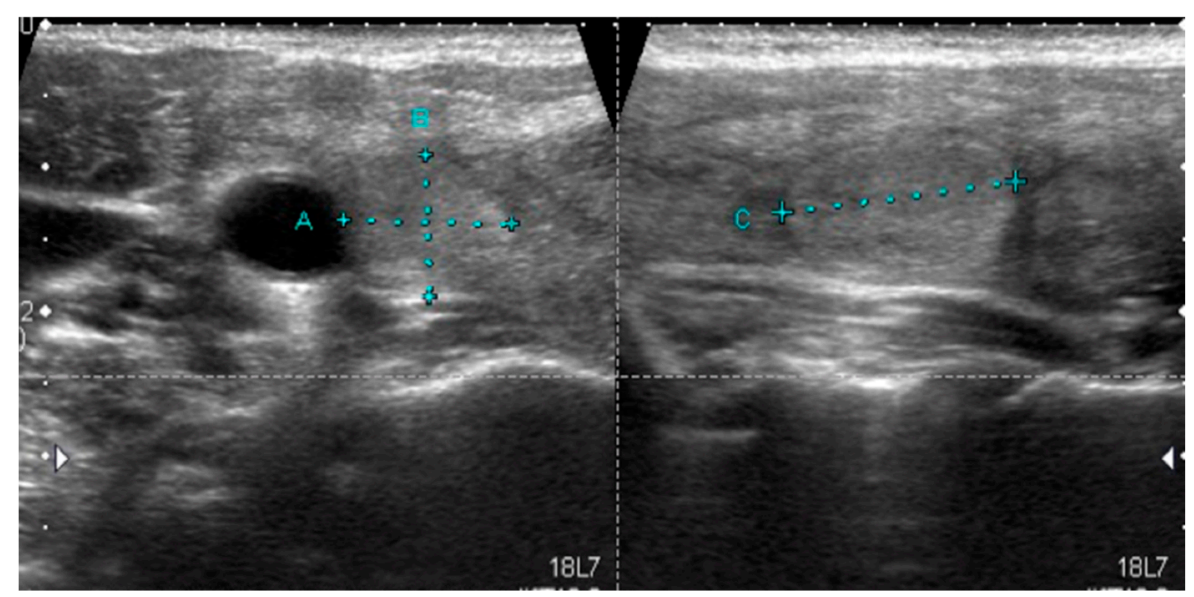

Figure 3. Typical sonographic pattern of RAS-positive NIFTP, normoechoic lesion with well-defined margins and without calcifications.

According to the 2017 WHO classification, two subtypes of FV PTC are distinguished: Invasive encapsulated FV PTC (i.e., the encapsulated FV with capsular or vascular invasion), and infiltrative FV, which is not encapsulated [11]. Invasive EFV PTC is associated with RAS mutation or PAX8-PPAR $\gamma$ and it constitutes $4 \%$ of all PTCs. Infiltrative FV accounts for $6 \%$ of all PTCs and is mainly caused by $B R A F$ mutation, usually $B R A F^{K 601 E}$, or, less often, $R A S$ mutation $[12,21,28,40]$. BRAF mutations are therefore typical for the more aggressive infiltrative FV PTC while RAS mutations are often found in the less aggressive invasive EFV or the above-described NIFTP. US features of FV can suggest the tumor behavior and molecular landscape, as it can have typical PTC-like US patterns with hypoechoic lesions with irregular blurred margins and, sometimes, microcalcifications or rather follicular neoplasm-like patterns, without these markers of potential malignancy. Infiltrative FV is frequently a hypoechoic lesion, with spiculated/microlobulated margins. Microcalcifications can be present in about $20 \%$ of the cases. Nodules are often ovoid to round in shape, with a non-parallel orientation and mixed vascularization. The presence of microcalcifications is less common in the FV than in the classic variant of PTC (41.2\% vs. 17.6\%) [31,39]. Invasive encapsulated FV is typically a hypoechoic lesion 
with rather smooth margins and no calcifications. Nodule shape, orientation, and vascularity are similar to the infiltrative type of FV [31,39]. Similar observations concerning more benign US features of nodules harboring RAS mutations were presented by Rossi et al. [25], who demonstrated that most of them were isoechoic. Nodules bearing $R A S$ mutations were also larger than nodules with $B R A F^{V 600 E}$ mutations $(>1 \mathrm{~cm}$ ) [25]. Interestingly, de Napoli et al. [54] observed microcalcifications and irregular margins in nodules with $N-R A S$ mutation. US examination is a very good prognostic tool in examining follicular-patterned lesions with papillary nuclear features as the infiltrative FV PTC may be differentiated from the benign NIFTP on the basis of the US pattern. However, US-based discrimination between invasive EFVs and NIFTPs is rather impossible in clinical practice [12,55]. The presence of RAS mutations is usually associated with less aggressive forms of PTC and a more benign US image (Figure 4).

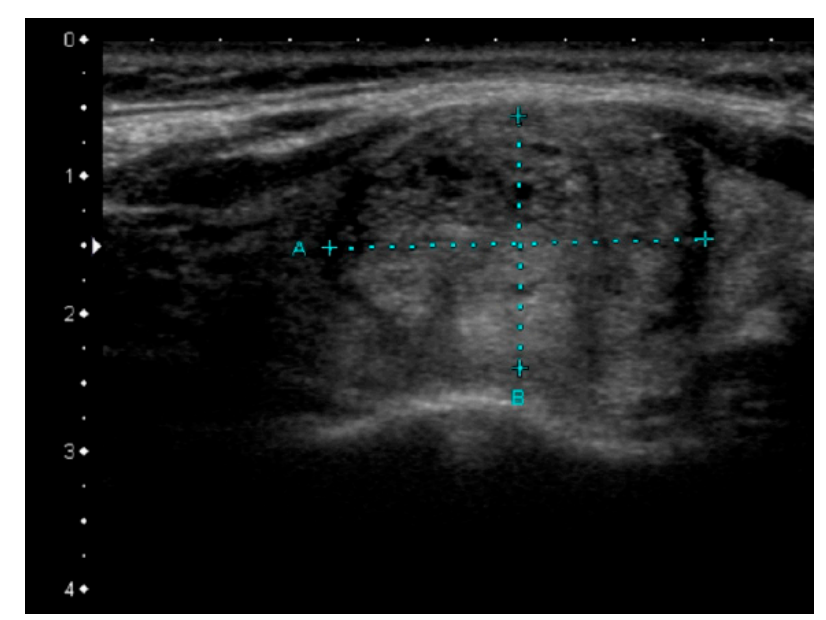

Figure 4. Sonographic pattern of RAS-positive papillary thyroid carcinima, slightly hypoechoic, heterogeneous lesion with rather well-defined margins.

However, follicular adenomas and carcinomas [56], and even poorly differentiated [57] and anaplastic [58] thyroid carcinomas, can bear RAS mutations. In such cases, the US findings are significantly different from those of NIFTP or invasive encapsulated FV of PTC. The differences in the sonographic pattern of thyroid follicular adenoma and carcinoma are well described, despite the fact that both of them harbor RAS mutations [56]. Thus, although PTCs with RAS mutations often have more benign US patterns than those with $B R A F$ mutations, the presence of $R A S$ mutations cannot be determined by any particular sonographic findings. In $R A S$-positive highly aggressive thyroid carcinomas, the US pattern is commonly very suspicious, definitely belonging to the ATA high-risk group [3].

\subsection{TERT Promoter Mutations}

The frequency of the TERT promoter mutation is reported as $21 \%, 12 \%$, and $9 \%$ in the classic, hobnail, and cribriform-morular variant (CMV) of PTC, respectively $[18,33,59]$. The presence of the TERT promoter mutation is strongly associated with older age, less-differentiated PTC, and a high risk of recurrence. TERT promoter mutations were suggested to be useful surrogate markers for high-risk PTC [60]. The US pattern is highly suspicious in all PTC variants harboring TERT promoter mutations. Tumors are typically multifocal, microlobulated, and hypoechoic with microcalcifications, and multiple lymph node metastases are frequently present [12,33]. Kim et al. [60] recently reported that a non-parallel orientation and microlobulated margin of the nodule were independent sonographic findings for predicting TERT promoter-mutated PTC in patients older than 50 years. 


\subsection{Other Mutations in Different Variants of PTC}

Several different gene mutations, rarely occurring in PTCs, were described in uncommon variants, such as the DICER1 mutation in a solid/trabecular variant [61]. The solid/trabecular variant of PTC is very rare, and constitutes about $3 \%$ of all PTCs. It occurs more commonly in children and young adults, especially in patients with a medical history of radiation. Histologically, this variant should be distinguished from poorly differentiated thyroid carcinomas, as they demonstrate similar solid, insular, and trabecular growth patterns. In US, these tumors usually have typical malignant features (i.e., hypoechogenicity, microcalcifications, irregular margins), but well-defined margins were also occasionally described [12]. Extrathyroidal extension and lymph node involvement are typically observed in US. A single case of $B R A F^{V K 600-1 E}$ mutation was also described in this variant of PTC [62].

Several mutations were described in the exceptionally uncommon cribriform-morular variant (CMV) - a variant of PTC that is usually associated with autosomal dominant inherited familial adenomatous polyposis (FAP). Sporadic isolated cases are very rare $[63,64]$. Tumors are often multiple. In patients with FAP, CMV PTC may occur first, before colonic manifestations are present. These tumors are often associated with mutations of CTNNB1, APC [65-67]. They have sonographic "benign-like" features, although their biological behavior can be very different, and is quite frequently very aggressive. In US, the tumor is frequently solid, oval to round, circumscribed, heterogeneous, and hypoechoic, without a hypoechoic halo or calcifications [12,67-69]. Histologically, CMV is characterized by the papillary growth of tall columnar cells, a cribriform pattern, lack of colloids, and the presence of spindle cells, squamoid morules, and nuclear clearing. $\beta$-catenin immunostaining is a hallmark of CMV PTC, both in sporadic cases and in cases associated with FAP $[67,68]$. As it was indicated above, CMV may be associated with TERT promoter mutations [59]. Several other different gene mutations were reported in CMV PTC, including K-RAS mutation [70], RET/PTC rearrangement, [71], and PIK3CA [72]. Unfortunately, no data is available on potential differences between CMVs harboring each of these mutations.

Associations between the genetic landscape and US features of PTC may be observed only for the most common mutations, due to the lack of published data in the cases of rare genetic alterations. Thus, we summarized the reports that provide the largest number of cases and the most detailed description of both US features and molecular findings. The observed correlations between molecular and sonographic aspects of PTC are presented in Table 1.

Table 1. Correlations between genetic drivers and sonographic findings in PTC, with respect to the specific PTC variants.

\begin{tabular}{|c|c|c|}
\hline Mutation & Tumor US Features and References & PTC Variant \\
\hline \multirow[t]{2}{*}{$B R A F^{V 600 E}$} & $\begin{array}{c}\text { solid structure }[12,23,31,34,35] \\
\text { hypoechogenicity }[12,23-26,31,34,35] \\
\text { microcalcifications }[12,22-26,31,33] \\
\text { macrocalcifications [31] } \\
\text { taller-then-wide shape } \\
{[23,29,34,35] / \text { non-parallel orientations [31] }} \\
\text { spiculated/microlobulated/irregular margin } \\
{[12,23,24,31]} \\
\text { absent halo [26] } \\
\text { ill-defined margin }[22,26] \\
\text { lymph node metastases }[12,24,33] \\
\text { extrathyroidal extension }[12,24] \\
\text { mixed type vascularity }[31]\end{array}$ & $\begin{array}{c} \\
\text { classic, } \\
\text { tall cell, } \\
\text { columnar cell } \\
\text { hobnail } \\
\text { Warthin-like } \\
\text { solid } \\
\text { microcarcinoma }\end{array}$ \\
\hline & $\begin{array}{c}\text { iso- or hypoechogenicity [31] } \\
\text { smooth or spiculated/microlobulated margins } \\
{[31]} \\
\text { no microcalcifications [31] } \\
\text { possible macrocalcifications [31] } \\
\text { non-parallel orientation [31] } \\
\text { mixed vascularity [31] }\end{array}$ & Hürthle cell \\
\hline
\end{tabular}


Table 1. Cont.

\begin{tabular}{|c|c|c|}
\hline Mutation & Tumor US Features and References & PTC Variant \\
\hline$B R A F^{K 601 E}$ & $\begin{array}{c}\text { hypoechogenicity [31,39] } \\
\text { spiculated/microlobulated margins [31,39] } \\
\text { microcalcifications }(20 \%)[31,39]\end{array}$ & infiltrative FV PTC \\
\hline \multirow[t]{2}{*}{$R A S$} & $\begin{array}{c}\text { hypoechogenicity [31] } \\
\text { smooth margins [31] } \\
\text { no microcalcifications [31] } \\
\text { ovoid-to-round shape [29] } \\
\text { mixed vascularization [29] } \\
\text { non-parallel orientation }[29,39]\end{array}$ & invasive EFV PTC \\
\hline & $\begin{array}{c}\text { iso-/hyperechogenicity }[46,50,51] \\
\text { well-defined margins }[46,50,51] \\
\text { no calcifications }[46,50,51]\end{array}$ & NIFTP \\
\hline \multirow[t]{2}{*}{ RET/PTC rearrangement } & $\begin{array}{c}\text { diffuse involvement of one or both thyroid } \\
\text { lobes [12,37] } \\
\text { scattered microcalcifications }[12,37] \\
\text { heterogeneous, mostly hypoechoic [12] } \\
\text { ill-defined margins [12,37] } \\
\text { nodule may not be defined (a "snowstorm" } \\
\text { pattern) [12] } \\
\text { hypo-/isoechogenicity [12,37] } \\
\text { lymph node involvement with nodal } \\
\text { microcalcifications }[12,37]\end{array}$ & diffuse sclerosing \\
\hline & $\begin{array}{l}\text { small nodule size [19] } \\
\text { hypoechogenicity [19] } \\
\text { microcalcifications [19] } \\
\text { ill-defined margins [19] }\end{array}$ & classic \\
\hline$P A X 8-P P A R \gamma$ & $\begin{array}{l}\text { hypoechogenicity [31] } \\
\text { smooth margins [31] } \\
\text { no calcifications [31] } \\
\text { ovoid-to-round shape [31] } \\
\text { mixed vascularization [31] }\end{array}$ & invasive EFV PTC \\
\hline $\begin{array}{c}C T N N B 1 \\
A P C\end{array}$ & $\begin{array}{c}\text { multiple tumors }[12,65,66] \\
\text { solid structure }[12,65,66] \\
\text { hypoechogenicity }[12,65] \\
\text { oval shape }[12,65] \\
\text { well circumscribed }[12,65] \\
\text { absence of hypoechoic halo }[12] \\
\text { absence of calcifications }[12,65]\end{array}$ & cribriform-morular \\
\hline TERT promoter & $\begin{array}{c}\text { hypoechogenicity }[12,33] \\
\text { microcalcifications }[12,33] \\
\text { non-parallel orientation [60] } \\
\text { microlobulated margins [60] }\end{array}$ & $\begin{array}{l}\text { cribriform-morular } \\
\text { hobnail } \\
\text { classic }\end{array}$ \\
\hline
\end{tabular}

\section{Conclusions}

On the basis of the current literature data, sonographic features of PTCs correlate with their molecular drivers, particularly between tumors harboring $B R A F^{V 600 E}$ versus activating RAS mutations, although many of these findings appear to be dependent on the tumor variant. Suspicious US findings, such as hypoechogenicity, spiculated/microlobulated margins, non-parallel orientation, taller-than-wide shape, and the presence of microcalcifications, are typical for PTC harboring $B R A F^{V 600 E}$ mutations. On the contrary, tumors with $R A S$ mutations are most frequently hypo- or isoechoic, and ovoid to round in shape, with smooth margins and without calcifications. There are also some US features typical for PTCs harboring other mutations, including $B R A F^{K 601 E}, R E T / P T C$ rearrangement, PAX8-PPAR $\gamma$, $C T N N B 1$, and $A P C$. However, further research is necessary, as some rare PTC variants still cannot be reliably analyzed due to the scarce literature, and some authors question even the widely described correlations between $B R A F^{V 600 E}$ and the typical suspicious US pattern. 
Supplementary Materials: The following are available online at http://www.mdpi.com/2077-0383/8/11/1916/s1, Figure S1: Study selection flowchart outlining the protocol adopted in this review based on the Preferred Reporting Items for Systematic Reviews and Meta-Analyses (PRISMA) Four-Phase Flow Diagram.

Author Contributions: Conceptualization, A.L. and M.S.; methodology, A.L. and M.S.; validation, A.L., M.S. and Z.A.; formal analysis, A.L. and M.S.; investigation, A.L., M.S., Z.A., A.Z. and M.K.-L.; data curation, A.L., M.S., Z.A., A.Z., M.K.-L. and L.M.; writing—original draft preparation, A.L. and M.S.; writing—review and editing, A.L., M.S., Z.A. and M.K.-L.; supervision, A.L., M.S. and M.K.-L.; project administration, A.L., M.S., Z.A., A.Z., M.K.-L. and L.M.; funding acquisition, A.L.

Funding: Medical University of Lodz, Lodz, Poland, grant No. 503/1-107-03/503-11-001-19-00.

Conflicts of Interest: The authors declare no conflict of interest.

\section{Abbreviations}

$\begin{array}{ll}\text { ACR } & \text { American College of Radiology } \\ \text { ATA } & \text { American Thyroid Association } \\ \text { DSV } & \text { Diffuse sclerosing variant } \\ \text { EFV } & \text { Encapsulated follicular variant } \\ \text { ETA } & \text { European Thyroid Association } \\ \text { FAP } & \text { Familial adenomatous polyposis } \\ \text { FNAB } & \text { Fine needle aspiration biopsy } \\ \text { FV } & \text { Follicular variant } \\ \text { NIFTP } & \text { Non-invasive follicular thyroid neoplasm with papillary-like nuclear features } \\ \text { PTC } & \text { Papillary thyroid carcinoma } \\ \text { US } & \text { Ultrasound } \\ \text { WV } & \text { Warthin-like variant }\end{array}$

\section{References}

1. Cancer Genome Atlas Research Network. Integrated genomic characterization of papillary thyroid carcinoma. Cell 2014, 159, 676-690. [CrossRef] [PubMed]

2. Szczepanek-Parulska, E.; Woliński, K.; Stangierski, A.; Gurgul, E.; Biczysko, M.; Majewski, P.; Rewaj-Łosyk, M.; Ruchała, M. Comparison of diagnostic value of conventional ultrasonography and shear wave elastography in the prediction of thyroid lesions malignancy. PLoS ONE 2013, 8, e81532. [CrossRef] [PubMed]

3. Haugen, B.R.; Alexander, E.K.; Bible, K.C.; Doherty, G.M.; Mandel, S.J.; Nikiforov, Y.E.; Pacini, F.; Randolph, G.W.; Sawka, A.M.; Schlumberger, M.; et al. 2015 American Thyroid Association management guidelines for adult patients with thyroid nodules and differentiated thyroid cancer: The American Thyroid Association Guidelines Task Force on thyroid nodules and differentiated thyroid cancer. Thyroid 2016, 26, 131-133. [CrossRef] [PubMed]

4. Russ, G.; Bonnema, S.J.; Erdogan, M.F.; Durante, C.; Ngu, R.; Leenhardt, L. European Thyroid Association guidelines for ultrasound malignancy risk stratification of thyroid nodules in adults: The EU-TIRADS. Eur. Thyroid J. 2017, 6, 225-237. [CrossRef] [PubMed]

5. Shin, J.H.; Baek, J.H.; Chung, J.; Ha, E.J.; Kim, J.H.; Lee, Y.H.; Lim, H.K.; Moon, W.J.; Na, D.G.; Park, J.S.; et al. Ultrasonography diagnosis and imaging-based management of thyroid nodules: Revised Korean Society of Thyroid Radiology consensus statement and recommendations. Korean J. Radiol. 2016, 17, 370-395. [CrossRef] [PubMed]

6. Adamczewski, Z.; Lewiński, A. Proposed algorithm for management of patients with thyroid nodules/focal lesions, based on ultrasound (US) and fine-needle aspiration biopsy (FNAB); our own experience. Thyroid Res. 2013, 6, 6. [CrossRef] [PubMed]

7. Lewiński, A.; Adamczewski, Z. Ultrasound and cytological diagnostics of thyroid-Its proper application in case of coexisting disturbing clinical signs and symptoms, suggestive of active proliferative lesion. Thyroid Res. 2015, 8 (Suppl. 1), A19. [CrossRef]

8. Lewiński, A.; Adamczewski, Z. Decision making for surgery in the suspect thyroid nodule. (Proper application of ultrasound (US) and fine needle aspiration biopsy (FNAB) completed but do not replace coexisting worrying clinical signs and symptoms). Thyroid Int. 2013, 1, 3-18. 
9. Stasiak, M.; Tymoniuk, B.; Adamczewski, Z.; Stasiak, B.; Lewiński, A. Sonographic pattern of subacute thyroiditis is HLA-dependent. Front. Endocrinol. 2019, 10, 3. [CrossRef]

10. Nikiforov, Y.E.; Seethala, R.R.; Tallini, G.; Baloch, Z.W.; Basolo, F.; Thompson, L.D.; Barletta, J.A.; Wenig, B.M.; Al Ghuzlan, A.; Kakudo, K.; et al. Nomenclature revision for encapsulated follicular variant of papillary thyroid carcinoma: A paradigm shift to reduce overtreatment of indolent tumors. JAMA Oncol. 2016, 2, 1023-1029. [CrossRef]

11. Lloyd, R.V.; Osamura, R.Y.; Klöppel, G.; Rosai, J. WHO classification of tumours of the thyroid gland. In WHO Classification of Tumours of Endocrine Organs, 4th ed.; International Agency for Research on Cancer: Lyon, France, 2017.

12. Shin, J.H. Ultrasonographic imaging of papillary thyroid carcinoma variants. Ultrasonography 2017, 36, 103-110. [CrossRef] [PubMed]

13. Gharib, H.; Papini, E.; Garber, J.R.; Duick, D.S.; Harrell, R.M.; Hegedüs, L.; Paschke, R.; Valcavi, R.; Vitti, P.; AACE/ACE/AME Task Force on Thyroid Nodules. American Association of Clinical Endocrinologists, American College of Endocrinology, and Associazione Medici Endocrinologi medical guidelines for clinical practice for the diagnosis and management of thyroid nodules-2016 Update. Endocr. Pract. 2016, 22, 622-639. [CrossRef] [PubMed]

14. Tessler, F.N.; Middleton, W.D.; Grant, E.G.; Hoang, J.K.; Berland, L.L.; Teefey, S.A.; Cronan, J.J.; Beland, M.D.; Desser, T.S.; Frates, M.C.; et al. ACR Thyroid Imaging, Reporting and Data System (TI-RADS): White paper of the ACR TI-RADS Committee. J. Am. Coll. Radiol. 2017, 14, 587-595. [CrossRef] [PubMed]

15. Dobruch-Sobczak, K.S.; Krauze, A.; Migda, B.; Mlosek, K.; Słapa, R.Z.; Bakuła-Zalewska, E.; Adamczewski, Z.; Lewiński, A.; Jakubowski, W.; Dedecjus, M. Integration of sonoelastography into the TIRADS lexicon could influence the classification. Front. Endocrinol. 2019, 10, 127. [CrossRef]

16. Nikiforov, Y.E.; Ohori, N.P.; Hodak, S.P.; Carty, S.E.; LeBeau, S.O.; Ferris, R.L.; Yip, L.; Seethala, R.R.; Tublin, M.E.; Stang, M.T.; et al. Impact of mutational testing on the diagnosis and management of patients with cytologically indeterminate thyroid nodules: A prospective analysis of 1056 FNA samples. J. Clin. Endocrinol. Metab. 2011, 96, 3390-3397. [CrossRef]

17. Menicali, E.; Moretti, S.; Voce, P.; Romagnoli, S.; Avenia, N.; Puxeddu, E. Intracellular signal transduction and modification of the tumor microenvironment induced by RET/PTCs in papillary thyroid carcinoma. Front. Endocrinol. 2012, 3, 67. [CrossRef]

18. Colombo, C.; Muzza, M.; Proverbio, M.C.; Tosi, D.; Soranna, D.; Pesenti, C.; Rossi, S.; Cirello, V.; De Leo, S.; Fusco, N.; et al. Impact of mutation density and heterogeneity on papillary thyroid cancer clinical features and remission probability. Thyroid 2019, 29, 237-251. [CrossRef]

19. Adeniran, A.J.; Zhu, Z.; Gandhi, M.; Steward, D.L.; Fidler, J.P.; Giordano, T.J.; Biddinger, P.W.; Nikiforov, Y.E. Correlation between genetic alterations and microscopic features, clinical manifestations, and prognostic characteristics of thyroid papillary carcinomas. Am. J. Surg. Pathol. 2006, 30, 216-222. [CrossRef]

20. Yip, L. Molecular markers for thyroid cancer diagnosis, prognosis, and targeted therapy. J. Surg. Oncol. 2015, 111, 43-50. [CrossRef]

21. Trovisco, V.; Vieira de Castro, I.; Soares, P.; Maximo, V.; Silva, P.; Magalhaes, J.; Abrosimov, A.; Guiu, X.M.; Sobrinho-Simões, M. BRAF mutations are associated with some histological types of papillary thyroid carcinoma. J. Pathol. 2004, 202, 247-251. [CrossRef]

22. Wang, S.; Liu, Z.; Sun, S.; Li, X.; Zeng, W.; Xiong, Y.; Guo, Y.; Wang, J.; Wang, Y.; Liu, C.; et al. Ultrasound features suspicious for malignancy predict the risk of BRAF mutation in papillary thyroid carcinoma. Int. J. Clin. Exp. Med. 2017, 10, 9470-9475.

23. Lee, E.J.; Song, K.H.; Kim, D.L.; Jang, Y.M.; Hwang, T.S.; Kim, S.K. The BRAF(V600E) mutation is associated with malignant ultrasonographic features in thyroid nodules. Clin. Endocrinol. 2011, 75, 844-850. [CrossRef] [PubMed]

24. Khadra, H.; Deniwar, A.; Mohsin, K.; Monlezun, D.; Kandil, E. Can suspicious ultrasound features predict BRAFV600E status in papillary thyroid cancer? Eur. Thyroid J. 2018, 7, 205-210. [CrossRef]

25. Rossi, M.; Buratto, M.; Tagliati, F.; Rossi, R.; Lupo, S.; Trasforini, G.; Lanza, G.; Franceschetti, P.; Bruni, S.; Degli Uberti, E.; et al. Relevance of BRAF(V600E) mutation testing versus RAS point mutations and RET/PTC rearrangements evaluation in the diagnosis of thyroid cancer. Thyroid 2015, 25, 221-228. [CrossRef] [PubMed] 
26. Kabaker, A.S.; Tublin, M.E.; Nikiforov, Y.E.; Armstrong, M.J.; Hodak, S.P.; Stang, M.T.; McCoy, K.L.; Carty, S.E.; Yip, L. Suspicious ultrasound characteristics predict BRAF V600E-positive papillary thyroid carcinoma. Thyroid 2012, 22, 585-589. [CrossRef] [PubMed]

27. Moon, H.J.; Kwak, J.Y.; Kim, E.K.; Kim, M.J. A taller-than-wide shape in thyroid nodules in transverse and longitudinal ultrasonographic planes and the prediction of malignancy. Thyroid 2011, 21, 1249-1253. [CrossRef]

28. Fagin, J.A.; Wells, S.A., Jr. Biologic and clinical perspectives on thyroid cancer. N. Engl. J. Med. 2016, 375, 1054-1067. [CrossRef]

29. Park, A.Y.; Son, E.J.; Kim, J.A.; Youk, J.H.; Park, Y.J.; Park, C.S.; Chang, H.S. Associations of the BRAFV600E mutation with sonographic features and clinicopathologic characteristics in a large population with conventional papillary thyroid carcinoma. PLoS ONE 2014, 9, e110868. [CrossRef]

30. Fakhruddin, N.; Jabbour, M.; Novy, M.; Tamim, H.; Bahmad, H.; Farhat, F.; Zaatari, G.; Aridi, T.; Kriegshauser, G.; Oberkanins, C.; et al. BRAF and NRAS mutations in papillary thyroid carcinoma and concordance in BRAF mutations between primary and corresponding lymph node metastases. Sci. Rep. 2017, 5, 4666. [CrossRef]

31. Baek, H.J.; Kim, D.W.; Shin, G.W.; Heo, Y.J.; Baek, J.W.; Lee, Y.J.; Cho, Y.J.; Park, H.K.; Ha, T.K.; Kim, D.H.; et al. Ultrasonographic features of papillary thyroid carcinomas according to their subtypes. Front. Endocrinol. 2018, 9, 223. [CrossRef]

32. Chen, J.H.; Faquin, W.C.; Lloyd, R.V.; Nosé, V. Clinicopathological and molecular characterization of nine cases of columnar cell variant of papillary thyroid carcinoma. Mod. Pathol. 2011, 24, 739-749. [CrossRef] [PubMed]

33. Watutantrige-Fernando, S.; Vianello, F.; Barollo, S.; Bertazza, L.; Galuppini, F.; Cavedon, E.; Censi, S.; Benna, C.; Ide, E.C.; Parisi, A.; et al. The hobnail variant of papillary thyroid carcinoma: Clinical/molecular characteristics of a large monocentric series and comparison with conventional histotypes. Thyroid 2018, 28, 96-103. [CrossRef] [PubMed]

34. Kim, G.R.; Shin, J.H.; Hahn, S.Y.; Ko, E.Y.; Oh, Y.L. Ultrasonographic features and clinical characteristics of Warthin-like variant of papillary thyroid carcinoma. Endocr. J. 2016, 63, 329-335. [CrossRef] [PubMed]

35. Ning, C.; Koo, J.S.; Kim, E.K.; Lee, S. Clinical and sonographic characteristics of Warthin-like variant papillary thyroid carcinomas. Med. Ultrason. 2019, 21, 152-157. [CrossRef] [PubMed]

36. Zhang, Q.; Liu, B.J.; Ren, W.W.; He, Y.P.; Li, X.L.; Zhao, C.K.; Zhang, Y.F.; Yue, W.W.; Zheng, J.Y.; Xu, H.X. Association between BRAF V600E Mutation and ultrasound features in papillary thyroid carcinoma patients with and without Hashimoto's thyroiditis. Sci. Rep. 2017, 7, 4899. [CrossRef] [PubMed]

37. Joung, J.Y.; Kim, T.H.; Jeong, D.J.; Park, S.M.; Cho, Y.Y.; Jang, H.W.; Jung, Y.Y.; Oh, Y.L.; Yim, H.S.; Kim, Y.L.; et al. Diffuse sclerosing variant of papillary thyroid carcinoma: Major genetic alterations and prognostic implications. Histopathology 2016, 69, 45-53. [CrossRef] [PubMed]

38. Li, Q.; Yuan, J.; Wang, Y.; Zhai, Y. Association between the BRAF V600E mutation and ultrasound features of the thyroid in thyroid papillary carcinoma. Oncol. Lett. 2017, 14, 1439-1444. [CrossRef]

39. Hughes, N.M.; Nae, A.; Barry, J.; Fitzgerald, B.; Feeley, L.; Sheahan, P. Sonographic differences between conventional and follicular variant papillary thyroid carcinoma. Eur. Arch. Otorhinolaryngol. 2017, 274, 2907-2913. [CrossRef]

40. Rivera, M.; Ricarte-Filho, J.; Knauf, J.; Shaha, A.; Tuttle, M.; Fagin, J.A.; Ghossein, R.A. Molecular genotyping of papillary thyroid carcinoma follicular variant according to its histological subtypes (encapsulated vs infiltrative) reveals distinct BRAF and RAS mutation patterns. Mod. Pathol. 2010, 23, 1191-1200. [CrossRef]

41. Howitt, B.E.; Jia, Y.; Sholl, L.M.; Barletta, J.A. Molecular alterations in partially-encapsulated or well-circumscribed follicular variant of papillary thyroid carcinoma. Thyroid 2013, 23, 1256-1262. [CrossRef]

42. Zhao, L.; Dias-Santagata, D.; Sadow, P.M.; Faquin, W.C. Cytological, molecular, and clinical features of noninvasive follicular thyroid neoplasm with papillary-like nuclear features versus invasive forms of follicular variant of papillary thyroid carcinoma. Cancer Cytopathol. 2017, 125, 323-331. [CrossRef] [PubMed]

43. Paulson, V.A.; Shivdasani, P.; Angell, T.E.; Cibas, E.S.; Krane, J.F.; Lindeman, N.I.; Alexander, E.K.; Barletta, J.A. Noninvasive follicular thyroid neoplasm with papillary-like nuclear features accounts for more than half of "carcinomas" harboring RAS mutations. Thyroid 2017, 27, 506-511. [CrossRef] [PubMed]

44. Geramizadeh, B.; Maleki, Z. Non-invasive follicular thyroid neoplasm with papillary-like nuclearfeatures (NIFTP): A review and update. Endocrine 2019, 64, 433-440. [CrossRef] [PubMed] 
45. Nikiforov, Y.E.; Baloch, Z.W.; Hodak, S.P.; Giordano, T.J.; Lloyd, R.V.; Seethala, R.R.; Wenig, B.M. Change in diagnostic criteria for noninvasive follicular thyroid neoplasm with papillarylike nuclear features. JAMA Oncol. 2018, 4, 1125-1126. [CrossRef] [PubMed]

46. Rosario, P.W.; Mourão, G.F. Noninvasive follicular thyroid neoplasm with papillary-like nuclear features (NIFTP): A review for clinicians. Endocr. Relat. Cancer 2019, 26, R259-R266. [CrossRef]

47. Chandler, J.B.; Colunga, M.; Prasad, M.L.; Callender, G.G.; Quinn, C.; Chhieng, D.; Adeniran, A.J. Identification of distinct cytomorphologic features in the diagnosis of NIFTP at the time of preoperative FNA: Implications for patient management. Cancer Cytopathol. 2017, 125, 865-875. [CrossRef]

48. Afkhami, M.; Karunamurthy, A.; Chiosea, S.; Nikiforova, M.N.; Seethala, R.; Nikiforov, Y.E.; Coyne, C. Histopathologic and clinical characterization of thyroid tumors carrying the BRAF(K601E) mutation. Thyroid 2016, 26, 242-247. [CrossRef]

49. Johnson, D.N.; Furtado, L.V.; Long, B.C.; Zhen, C.J.; Wurst, M.; Mujacic, I.; Kadri, S.; Segal, J.P.; Antic, T.; Cipriani, N.A. Noninvasive follicular thyroid neoplasms with papillary-like nuclear features are genetically and biologically similar to adenomatous nodules and distinct from papillary thyroid carcinomas with extensive follicular growth. Arch. Pathol. Lab. Med. 2018, 142, 838-850. [CrossRef]

50. Yoon, J.H.; Kwon, H.J.; Kim, E.K.; Moon, H.J.; Kwak, J.Y. The follicular variant of papillary thyroid carcinoma: Characteristics of preoperative ultrasonography and cytology. Ultrasonography 2016, 35, 47-54. [CrossRef]

51. Hahn, S.Y.; Shin, J.H.; Lim, H.K.; Jung, S.L.; Oh, Y.L.; Choi, I.H.; Jung, C.K. Preoperative differentiation between noninvasive follicular thyroid neoplasm with papillary-like nuclear features (NIFTP) and non-NIFTP. Clin. Endocrinol. 2017, 86, 444-450. [CrossRef]

52. Rosario, P.W.; da Silva, A.L.; Nunes, M.B.; Borges, M.A.R. Risk of malignancy in thyroid nodules using the American College of Radiology thyroid imaging reporting and data system in the NIFTP era. Horm. Metab. Res. 2018, 50, 735-737. [CrossRef] [PubMed]

53. Rosario, P.W.; Silva, T.H.; de Oliveira, P.H.L. Impact of noninvasive follicular thyroid neoplasm with papillary-like nuclear features (NIFTP) on the risk of malignancy estimated by the ultrasonographic classification of the American Thyroid Association (ATA) in thyroid nodules $>1 \mathrm{~cm}$. Endocrine 2018, 60, 535-536. [CrossRef] [PubMed]

54. De Napoli, L.; Bakkar, S.; Ambrosini, C.E.; Materazzi, G.; Proietti, A.; Macerola, E.; Basolo, F.; Miccoli, P. Indeterminate Single Thyroid Nodule: Synergistic impact of mutational markers and sonographic features in triaging patients to appropriate surgery. Thyroid 2016, 26, 390-394. [CrossRef] [PubMed]

55. Rosario, P.W. Ultrasonography and cytology as predictors of noninvasive follicular thyroid (NIFTP) neoplasm with papillary-like nuclear features: Importance of the differential diagnosis with the invasive encapsulated follicular variant of papillary thyroid cancer. Clin. Endocrinol. 2017, 87, 635-636. [CrossRef]

56. Fukahori, M.; Yoshida, A.; Hayashi, H.; Yoshihara, M.; Matsukuma, S.; Sakuma, Y.; Koizume, S.; Okamoto, N.; Kondo, T.; Masuda, M.; et al. The associations between RAS mutations and clinical characteristics in follicular thyroid tumors: New insights from a single center and a large patient cohort. Thyroid 2012, 22, $683-689$. [CrossRef]

57. Ibrahimpasic, T.; Ghossein, R.; Shah, J.P.; Ganly, I. Poorly differentiated carcinoma of the thyroid gland: Current status and future prospects. Thyroid 2019, 29, 311-321. [CrossRef]

58. Bonhomme, B.; Godbert, Y.; Perot, G.; Al Ghuzlan, A.; Bardet, S.; Belleannée, G.; Crinière, L.; Do Cao, C.; Fouilloux, G.; Guyetant, S.; et al. Molecular pathology of anaplastic thyroid carcinomas: A retrospective study of 144 cases. Thyroid 2017, 27, 682-692. [CrossRef]

59. Oh, E.J.; Lee, S.; Bae, J.S.; Kim, Y.; Jeon, S.; Jung, C.K. TERT promoter mutation in an aggressive cribriform morular variant of papillary thyroid carcinoma. Endocr. Pathol. 2017, 28, 49-53. [CrossRef]

60. Kim, T.H.; Ki, C.S.; Hahn, S.Y.; Oh, Y.L.; Jang, H.W.; Kim, S.W.; Chung, J.H.; Shin, J.H. Ultrasonographic prediction of highly aggressive telomerase reverse transcriptase (TERT) promoter-mutated papillary thyroid cancer. Endocrine 2017, 57, 234-240. [CrossRef]

61. Ravella, L.; Lopez, J.; Descotes, F.; Lifante, J.C.; David, C.; Decaussin-Petrucci, M. DICER1 mutated, solid/trabecular thyroid papillary carcinoma in an 11-year-old child. Ann. Pathol. 2018, 38, 316-320. [CrossRef]

62. Trovisco, V.; Soares, P.; Soares, R.; Magalhães, J.; Sá-Couto, P.; Sobrinho-Simões, M. A new BRAF gene mutation detected in a case of a solid variant of papillary thyroid carcinoma. Hum. Pathol. 2005, 36, 694-697. [CrossRef] [PubMed] 
63. Lee, S.; Hong, S.W.; Shin, S.J.; Kim, Y.M.; Rhee, Y.; Jeon, B.I.; Moon, W.C.; Oh, M.R.; Lim, S.K. Papillary thyroid carcinoma associated with familial adenomatous polyposis: Molecular analysis of pathogenesis in a family and review of the literature. Endocr. J. 2004, 1, 317-323. [CrossRef] [PubMed]

64. Cetta, F.; Pelizzo, M.R.; Curia, M.C.; Barbarisi, A. Genetics and clinicopathological findings in thyroid carcinomas associated with familial adenomatous polyposis. Am. J. Pathol. 1999, 155, 7-9. [CrossRef]

65. Jung, C.K.; Choi, Y.J.; Lee, K.Y.; Bae, J.S.; Kim, H.J.; Yoon, S.K.; Son, Y.I.; Chung, J.H.; Oh, Y.L. The cytological, clinical, and pathological features of the cribriform-morular variant of papillary thyroid carcinoma and mutation analysis of CTNNB1 and BRAF genes. Thyroid 2009, 19, 905-913. [CrossRef]

66. Uchino, S.; Noguchi, S.; Yamashita, H.; Yamashita, H.; Watanabe, S.; Ogawa, T.; Tsuno, A.; Murakami, A.; Miyauchi, A. Mutational analysis of the APC gene in cribriform-morular variant of papillary thyroid carcinoma. World J. Surg. 2006, 30, 775-779. [CrossRef]

67. Xu, B.; Yoshimoto, K.; Miyauchi, A.; Kuma, S.; Mizusawa, N.; Hirokawa, M.; Sano, T. Cribriform-morular variant of papillary thyroid carcinoma: A pathological and molecular genetic study with evidence of frequent somatic mutations in exon 3 of the beta-catenin gene. J. Pathol. 2003, 199, 58-67. [CrossRef]

68. Chong, Y.; Shin, J.H.; Oh, Y.L.; Han, B.; Ko, E.Y. Cribriform-morular variant of papillary thyroid carcinoma: Ultrasonographic and clinical characteristics. Thyroid 2013, 23, 45-49. [CrossRef]

69. Pradhan, D.; Sharma, A.; Mohanty, S.K. Cribriform-morular variant of papillary thyroid carcinoma. Pathol. Res. Pract. 2015, 211, 712-716. [CrossRef]

70. Giannelli, S.M.; McPhaul, L.; Nakamoto, J.; Gianoukakis, A.G. Familial adenomatous polyposis-associated, cribriform morular variant of papillary thyroid carcinoma harboring a K-RAS mutation: Case presentation and review of molecular mechanisms. Thyroid 2014, 24, 1184-1189. [CrossRef]

71. Cameselle-Teijeiro, J.; Menasce, L.P.; Yap, B.K.; Colaco, R.J.; Castro, P.; Celestino, R.; Ruiz-Ponte, C.; Soares, P.; Sobrinho-Simoes, M. Cribriform-morular variant of papillary thyroid carcinoma: Molecular characterization of a case with neuroendocrine differentiation and aggressive behavior. Am. J. Clin. Pathol. 2009, 131, 134-142. [CrossRef]

72. Kwon, M.J.; Rho, Y.S.; Jeong, J.C.; Shin, H.S.; Lee, J.S.; Cho, S.J.; Nam, E.S. Cribriform-morular variant of papillary thyroid carcinoma: A study of 3 cases featuring the PIK3CA mutation. Hum. Pathol. 2015, 46, 1180-1188. [CrossRef] [PubMed] 